\title{
Typing Haemophilus ducreyi by indirect immunofluorescence assay
}

\author{
LINDA SLOOTMANS,* DIRK A VANDEN BERGHE,* AND PETER PIOT† \\ From the Laboratories of Microbiology, *University of Antwerp, and + Institute of Tropical Medicine, \\ Antwerp, Belgium
}

SUMMARY Rabbits were inoculated with untreated whole cells of 16 strains of Haemophilus ducreyi. Homologous titres in an indirect immunofluorescence test ranged from 1/320 to 1/1280. No cross reactions, or very few, were observed between antisera to these strains and 22 other (possible taxonomically related) species, strains, and genera. A large diversity in types of antigen was observed among the strains of $H$ ducreyi. Antiserum from two antigens (35000 and 3138), however, reacted with all $16 \mathrm{H}$ ducreyi antigens tested. At least nine of the strains of $H d u c r e y i$ examined could be identified as determining the type of antigen.

\section{Introduction}

Since the recent introduction of sensitive and selective media, Haemophilus ducreyi can now be isolated from most patients with chancroid. ${ }^{1-4}$ These isolation media are, however, only available in a few centres. Because of the high rate of isolation, epidemiological studies, such as studies of the mode of transmission, virulence, the question of relapse or reinfection, and geographical variation between strains of $\boldsymbol{H}$ ducreyi, are now possible. Markers are therefore needed to differentiate between strains.

$H$ ducreyi does not produce acid from sugars. The only biochemical activities reported are the reduction of nitrates to nitrites, the production of alkaline phosphatase, and the production of aminopeptidases with several substrates. ${ }^{356}$ All isolates show the same basic patterns of reaction, however, and differentiation on the basis of biotyping has not been reported. Plasmid analysis and patterns of susceptibility to antimicrobials may only be useful within a short time. ${ }^{7}$ Odumeru et al reported variations in protein profiles of the outer membrane that were species specific, as determined by sodium dodecyl sulphatepolyacrylamide gel electrophoresis (SDS-PAGE). These profiles are stable and provide a basis for subtyping.

Better knowledge of the antigenic properties of the organism, and of serological reactions to it, may provide a useful tool in further epidemiological

Address for reprints: Dr L Slootmans, Labo Microbiologie, Universitaire Instelling Antwerpen, Universiteitsplein 1, B-2610 Wilrijk, Belgium

Accepted for publication 10 August 1984 studies as well as for serological diagnosis. In this study we used an indirect immunofluorescence assay to assess antigenic diversity in $H$ ducreyi. Immunofluorescence was selected, rather than precipitation, agglutination, or coagglutination, as $H$ ducreyi cells tend to clump. Clumping of the organism may have been one factor that prevented the development of a serotyping system in the early studies on $\mathrm{H}$ ducreyi. ${ }^{9}$

\section{Materials and methods}

STRAINS OF H DUCREYI, OTHER HAEMOPHILUS SPP, AND RELATED GENERA

Table I lists the strains of $H$ ducreyi used as immunogens. Five strains belonged to different SDS-PAGE subtypes as described by Odumeru et al. ${ }^{8}$ Other isolates included strains from Kenya (supplied by Professor H Nsanze), South Africa (Dr R C Ballard), Canada (Professor A R Ronald and Dr W Albritton), the Netherlands (Dr W Sturm), and the Pasteur Institute, Paris.

Table II lists serotypes of $H$ influenzae, other Haemophilus spp, and related genera used as immunogens. The serotypes of $H$ influenzae and the species $H$ paraphrohaemolyticus and $H$ pleuropneumoniae were kindly provided by $\mathrm{Dr} M$ Kilian. Other organisms studied included $H$ aegyptius (NCTC 8502), $H$ paraphrophilus (NCTC 10557), $H$ haemolyticus (NCTC 10659), $H$ equigenitalis (NCTC 11184), $H$ aphrophilus (NCTC 5886), $H$ avium (NCTC 3438) and Actinobacillus actinomycetemcomitans (NCTC 9709). Clinical isolates of Pasteurella gallinarum, $P$ haemolytica, $P$ ureae, $P$ pneumotropica, Eikenella corrodens, Bordetella pertussis, 
TABLE I Homologous titres obtained in the indirect immunofluorescent assay using 16 strains of Haemophilus ducreyi as immunogens

\begin{tabular}{llll}
\hline Strain No & Origin and source & $\begin{array}{l}\text { SDS-PAGE } \\
\text { subtype* }\end{array}$ & $\begin{array}{l}\text { Homologous } \\
\text { titre }\end{array}$ \\
\hline C148 & Kenya & $\mathrm{C}$ & $1 / 1280$ \\
BG411 & Kenya & $\mathrm{B}$ & $1 / 320$ \\
$36-\mathrm{F}-2$ & Pittman 1948 & $\mathrm{D}$ & $1 / 640$ \\
V1159 & Seattle & $\mathrm{F}$ & $1 / 640$ \\
35000 & Winnipeg & $\mathrm{E}$ & $1 / 640$ \\
3140 & Kenya (ITM) & & $1 / 640$ \\
IP7866 & Pasteur Institute & & $1 / 640$ \\
3105 & South Africa (ITM) & & $1 / 640$ \\
3115 & South Africa (ITM) & $1 / 640$ \\
2665 & South Africa (ITM) & & $1 / 640$ \\
2668 & South Africa (ITM) & & $1 / 640$ \\
3144 & Kenya (ITM) & & $1 / 640$ \\
3130 & The Netherlands (ITM) & & $1 / 640$ \\
3142 & Kenya (ITM) & $1 / 640$ \\
3138 & Kenya (ITM) & & $1 / 640$ \\
3120 & The Netherlands (ITM) & & \\
\hline
\end{tabular}

SDS-PAGE = sodium dodecyl suphate-polyacrylamide gel electrophoresis.

*According to Odumeru et al. ${ }^{8}$

ITM $=$ the collection of the Institute of Tropical Medicine, Antwerp, Belgium.

and $H$ parainfluenzae were supplied by the Institute of Tropical Medicine, Antwerp.

IMMUNISATION

Cultures were grown on a medium consisting of Mueller-Hinton agar (BBL), 5\% calf serum (Gibco), $5 \%$ chocolatised horse blood (Gibco), and $2 \%$ IsoVitalex (BBL). Growth was scraped off after incubation for 48 hours at $35^{\circ} \mathrm{C}$ in a microaerophilic atmosphere, and was suspended in sterile phosphate buffered saline (PBS) (Oxoid). The organisms were washed three times, and the wet weight was adjusted to $15 \mathrm{~g} / \mathrm{l}$.

New Zealand white rabbits weighing about $3 \mathrm{~kg}$ were bled and then immunised with the suspensions, given in separate doses, as follows: $0.4 \mathrm{ml}$ antigen in $0.4 \mathrm{ml}$ complete Freund's adjuvant (Difco) subcutaneously in four sites on the back on day 1; $0.25 \mathrm{ml}$ intramuscularly into each hind quarter on day 14; and $0.5 \mathrm{ml}, 1 \mathrm{ml}$, and $2 \mathrm{ml}$ intravenously on days 15,16 , and 17 . The animals were bled on day 26 if the immunisation was satisfactory-that is, if the serum gave a homologous titre of $1 / 320$ or more in the indirect immunofluorescence assay. If not, a $2 \mathrm{ml}$ booster was given intravenously, and the serum was harvested the following day and sterilised by filtration.

\section{PREPARATION OF ANTIGEN SLIDES}

Antigen for use in the immunofluorescence test was cultured in Mueller-Hinton broth (BBL) supplemented with $200 \mathrm{mg} / 1$ haemin hydrochloride (BDH), $5 \%$ horse serum (Gibco), and $2 \%$ IsoVitalex (BBL). After incubation for 24 hours at $35^{\circ} \mathrm{C}$ in $5 \%$ carbon dioxide, $2 \mathrm{ml}$ volumes of culture were washed three times and resuspended in $4 \mathrm{ml}$ PBS. The wells of multispot microscope slides (Wellcome) were filled with $50 \mu \mathrm{l}$ of this suspension. Slides were air dried and fixed for 10 minutes with $95 \%$ ethanol. They were rinsed twice in PBS and once in distilled water, dried, and stored for further use. Careful precautions

TABLE II Cross reactions between antiserum to five strains of Haemophilus ducreyi, other Haemophilus species, and related genera (heterologous titres expressed as percentages of homologous titres).

\begin{tabular}{|c|c|c|c|c|c|}
\hline \multirow[b]{2}{*}{ Organism used as antigen } & \multicolumn{5}{|c|}{ Antiserum to strains: } \\
\hline & $C 148$ & $B G 411$ & $36-F-2$ & $V 1159$ & 35000 \\
\hline \multicolumn{6}{|l|}{$H$ influenzae } \\
\hline Serotype a & $1 \cdot 5$ & 6 & $1 \cdot 5$ & 6 & 0.8 \\
\hline Serotype b & $0 \cdot 8$ & 3 & 0.8 & 3 & 3 \\
\hline Serotype c & $1 \cdot 5$ & $1 \cdot 5$ & $0 \cdot 3$ & 3 & 3 \\
\hline Serotype $d$ & 0.8 & 3 & 0.8 & 3 & 6 \\
\hline Serotype e & 0.8 & 3 & 0.8 & 6 & 3 \\
\hline Serotype $\mathrm{f}$ & 0.8 & $1 \cdot 5$ & $0 \cdot 3$ & 3 & 3 \\
\hline$H$ aegyptius & 0.8 & 3 & 0.8 & 3 & 3 \\
\hline H paraphrophilus & 0.8 & 3 & 0.8 & $1 \cdot 5$ & $1 \cdot 5$ \\
\hline$H$ parainfluenzae & $0 \cdot 8$ & 3 & $1 \cdot 5$ & 3 & 3 \\
\hline$H$ haemolyticus & 0.8 & 3 & 0.8 & 3 & 3 \\
\hline$H$ equigenitalis & $<0.8$ & $<1 \cdot 5$ & $<0.3$ & $<1 \cdot 5$ & $<0.8$ \\
\hline H aphrophilus & 1.5 & 3 & 0.3 & 1.5 & 3 \\
\hline$H$ avium & $1 \cdot 5$ & 3 & $0 \cdot 8$ & 13 & 3 \\
\hline H paraphrohaemolyticus & $1 \cdot 5$ & 6 & $1 \cdot 5$ & 3 & 3 \\
\hline H pleuropneumoniae & $<0.8$ & $<1 \cdot 5$ & $<0 \cdot 3$ & $<1 \cdot 5$ & 0.8 \\
\hline Pasteurella gallinarum & 0.8 & 3 & 0.8 & 6 & 3 \\
\hline$P$ haemolytica & $1 \cdot 5$ & 3 & $0 \cdot 3$ & $1 \cdot 5$ & 0.8 \\
\hline$P$ ureae & 6 & 13 & 13 & 13 & 6 \\
\hline P pneumotropica & 0.8 & 3 & $0 \cdot 8$ & 6 & 3 \\
\hline Eikenella corrodens & $<0 \cdot 8$ & $<1 \cdot 5$ & $<0 \cdot 3$ & $<1 \cdot 5$ & $<0.8$ \\
\hline Actinobacillus actinomycetemcomitans & 0.8 & $1 \cdot 5$ & 0.8 & 6 & 3 \\
\hline Bordetella pertussis & $1 \cdot 5$ & 6 & $1 \cdot 5$ & 13 & $1 \cdot 5$ \\
\hline
\end{tabular}


had to be taken to preserve antigen slides. They were packed and sealed individually in plastic bags with silica gel and kept at $-70^{\circ} \mathrm{C}$. Thus they could be preserved for several months without loss of immunofluorescence, which otherwise began to disappear after about one week.

\section{INDIRECT IMMUNOFLUORESCENCE ASSAY}

A $50 \mu \mathrm{l}$ volume of antiserum or diluted antiserum was applied to each well. After being incubated for 30 minutes at $37^{\circ} \mathrm{C}$ in a humid atmosphere, the slides were washed twice in PBS and twice in distilled water. The conjugate consisted of sheep anti-rabbit IgG $(\mathrm{h}+\mathrm{l})$ antibodies conjugated with fluorescein (Institut Pasteur). As counterstain, a volume of $50 \mu \mathrm{l}$ of $0.1 \%$ Evans blue (Merck) in PBS was applied to the wells. After being incubated for 30 minutes at $37^{\circ} \mathrm{C}$ in a humid atmosphere and washed twice in PBS and twice in distilled water, the slides were mounted with $50 \%$ glycerol in PBS and examined with a Leitz Dialux vertical illuminator microscope with a $\times 50$ water objective. Serum titres were the dilutions that retained full staining of the bacterial contour.

\section{Results}

Homologous titres of antibody in the serum varied from $1 / 320$ to $1 / 1280$ (table I). No reaction was observed between $H$ ducreyi strains and the control serum samples-that is, those taken before immunisation. Repeated testing with slides made from different batches of antigen from the same strains gave results that did not appreciably differ from the first results.

The specificity of the reactions was assessed by testing other taxonomically related species and genera with antiserum to five strains of $\boldsymbol{H}$ ducreyi. Table II shows the results of these tests, expressing the heterologous titres as percentages of the homologous titres. The most prominent cross reactions were three twofold dilutions less than the homologous titre, or $13 \%$. This occured in only five reactions out of 110; one with $H$ avium, three with $P$ ureae, and one with $B$ pertussis. On the basis of these results, heterologous titres of $25 \%$ or more of the homologous titre were considered to be specific for $H$ ducreyi.

Table III shows the homologous and heterologous cross reactions of all the immunogens and their antisera. Two way and one way cross reactions were common. Strains 35000 and 3138 were almost serologically identical, as the antiserum of strain 35000 reacted with all the antigens, and the antiserum of strain 3138 reacted with all but one. One antiserum (anti-C148) showed only a homologous reaction, and one antiserum (anti-3140) showed only one heterologous reaction, although strain $\mathrm{C} 148$ reacted with 13 heterologous antisera and strain 3140 reacted with 11 . Because of the reactivity of the antisera to strains 35000 and 3138 , no immunogen reacted only with its homologous antiserum.

\section{Discussion}

Antisera with high titres to $H$ ducreyi were succesfully raised in rabbits. The highest homologous titre observed was $1 / 1280$, and in most cases it reached $1 / 640$. Two rabbits responded to immunisation with very low titres $(1 / 320)$, but high titres were obtained when other animals were injected with the same antigen. Boosters given after the immunisation period of $\mathbf{2 6}$ days did not result in higher homologous titres.

Serological cross reactions sometimes occurred with other Haemophilus species and the genera

TABLE III Homologous and heterologous reactions between 16 strains of Haemophilus ducreyi and antisera to them (titres expressed as percentages of homologous titres).

\begin{tabular}{|c|c|c|c|c|c|c|c|c|c|c|c|c|c|c|c|c|}
\hline \multirow{2}{*}{$\begin{array}{l}\text { Strain No } \\
\text { used as } \\
\text { antigen }\end{array}$} & \multicolumn{16}{|c|}{ Antiserum to strains: } \\
\hline & $C 148$ & $B G 411$ & $36-F-2$ & $V 1159$ & 35000 & 3140 & IP7866 & 3105 & 3115 & 2665 & 2668 & 3144 & 3130 & 3142 & 3138 & 3120 \\
\hline C148 & 100 & & & 25 & 100 & 25 & 25 & 50 & 100 & 25 & 50 & 50 & 50 & 50 & 100 & 25 \\
\hline BG411 & & 100 & & 25 & 100 & & & & 25 & & & & & & 50 & 25 \\
\hline $36-F-2$ & & & 100 & & 50 & & & 25 & & & & & 25 & 25 & 50 & 25 \\
\hline V1159 & & 25 & 25 & 100 & 100 & & 25 & 25 & & & & 25 & 25 & 25 & 100 & \\
\hline 35000 & & 25 & 50 & 25 & 100 & & & & & 25 & & & & 50 & 50 & 25 \\
\hline 3140 & & & & 25 & 50 & 100 & & 25 & 25 & 25 & 50 & 50 & 50 & 25 & 50 & 25 \\
\hline IP7866 & & 25 & & & 50 & & 100 & & & & 25 & 25 & & 25 & 25 & 25 \\
\hline $\begin{array}{l}3105 \\
3115\end{array}$ & & & & 25 & 50 & & & 100 & & & & & & 25 & 50 & \\
\hline $\begin{array}{l}3115 \\
2665\end{array}$ & & & 25 & 25 & $\begin{array}{r}100 \\
25\end{array}$ & & & & 100 & & & 25 & & 25 & 50 & \\
\hline 2668 & & & & & 25 & & & & & 100 & 100 & & 25 & & $\begin{array}{l}50 \\
25\end{array}$ & \\
\hline 3144 & & & & 25 & 50 & & & & 25 & & & 100 & 25 & 25 & 50 & \\
\hline 3130 & & & & & 50 & & & & & & & & 100 & & & \\
\hline 3142 & & 25 & & & 25 & & & & 25 & & & & & 100 & 25 & 25 \\
\hline 3138 & & & & 25 & 50 & & & & & & & & & 25 & 100 & 25 \\
\hline 3120 & & & & 25 & 25 & & & & & & & & & & 25 & 100 \\
\hline
\end{tabular}


Pasteurella, Eikenella, Bordetella, and Actinobacillus, although only at up to three serum dilutions below the homologous titres. This suggests that $H$ ducreyi may have some unique antigenic determinants among Haemophilus spp and related genera.

The first five strains used as immunogen (table I) belonged to different SDS-PAGE subtypes. ${ }^{8}$ There were no cross reactions between strains C148, BG411, and 36-F-2 and antisera to them, and they seemed to be antigenically distinct (table III). In contrast, strains V1159 and 35000 showed multiple cross reactions between each other and with strains C148, BG411, and 36-F-2.

Two antisera (to strains 3138 and 35000 ) yielded an immunological reaction with all or most $H$ ducreyi antigens tested, and three antisera (to strains 3120 , 3142 , and V1159) reacted with eight to 10 of 15 heterologous antigens. The corresponding strains, however, reacted with relatively few antisera, making these antigens "senior" to most other strains. The opposite was the case for strains C148 and 3140 . Their antisera were very specific, but the immunogens reacted with most of the antisera. These two strains differed slightly in antigenic structure, however, as the heterologous reaction between antiserum to $\mathrm{C} 148$ and strain 3140 was considered to be negligible. Antisera against the senior strains may be very useful for identifying $H d u c r e y i$, as they are sensitive and specific for this species. Because of the many two way and one way cross reactions, however, these strains may be less useful for providing serum for serotyping or specific antigen types.

Each of the remaining strains reacted with up to three heterologous serum samples and showed a characteristic pattern of reactions. Each immunogen possessed a set of antigen determinants that were expressed in its homologous antiserum. Thus, as table IV shows, antigens could be identified by their reactions with the different antisera, which we numbered 1 to 9 , and could thus be classified presumptively as different types of antigen and numbered I to IX.

Our results indicated that the antigenic composition of $H$ ducreyi is complex. The indirect immunofluorescence assay with whole bacteria used as immunogen and as test antigen may not be sufficiently accurate to show this complexity. The specificity of the antiserum to antigens may be
TABLE IV Scheme for typing antigens to Haemophilus ducreyi

\begin{tabular}{llcl}
\hline $\begin{array}{l}\text { Type of } \\
\text { antigen }\end{array}$ & $\begin{array}{l}\text { No of } \\
\text { strain }\end{array}$ & $\begin{array}{l}\text { Homologous } \\
\text { antiserum }\end{array}$ & $\begin{array}{l}\text { Heterologous reaction } \\
\text { (25-50\% of homologous } \\
\text { titre) with antisera }\end{array}$ \\
\hline I & 3105 & 1 & \\
II & 2665 & 2 & \\
III & 3130 & 3 & 7 \\
IV & BG411 & 4 & 3 \\
V & 2668 & 5 & 7,3 \\
VI & 3144 & 6 & 6,8 \\
VII & 3115 & 7 & 1,3 \\
VIII & $36-F-2$ & 8 & $4,5,6$ \\
IX & IP7866 & 9 & \\
\hline
\end{tabular}

increased by immunisation with cell wall preparations or by using more specific techniques, such as immunoelectrophoresis or monoclonal antibody studies, to detect antigens specific for species and types. However, simple typing of $H$ ducreyi such as we reported here, without further knowledge of the detailed antigenic composition, may be useful in clinical and epidemiological studies.

We acknowledge a grant to $\mathrm{L} S$ from the Institut voor Wetenschappelijk Onderzoek in Nijverheid en Landbouw (IWONL), and to $P$ P from the National Fonds voor Wetenschappelijk Onderzoek (NFWO).

\section{References}

1. Oberhofer TR, Bach AE. Isolation and cultivation of Haemophilus ducreyi. J Clin Microbiol 1982; 15:625-9.

2. Sottnek FO, Biddle JW, Kraus SJ, Weaver RE, Stewart JA. Isolation and identification of Haemophilus ducreyi in a clinical study. J Clin Microbiol 1980;12:170-4.

3. Hammond GW, Lian CJ, Wilt JC, Ronald AR. Comparison of specimen collection and laboratory techniques for isolation of Haemophilus ducreyi. J Clin Microbiol 1978; 7:39-43.

4. Nsanze H, Plummer FA, Maggwa ABN, et al. Comparison of media for the primary isolation of Haemophilus ducreyi. Sex Transm Dis 1984;11:6-9.

5. Casin IM, Sanson-Le Pors MJ, Gorce MF, Ortenberg M, Pérol Y. The enzymatic profile of Haemophilus ducreyi. Ann Microbiol (Paris) 1982;133B: 379-88.

6. Kilian M. A taxonomic study of the genus Haemophilus, with the proposal of a new species. J Gen Microbiol 1976;93:9-62.

7. Handsfield HH, Totten PA, Fennel CL, Falkow S, Holmes KK. Molecular epidemiology of Haemophilus ducreyi infections. Ann Intern Med 1981;95:315-8.

8. Odumeru JA, Ronald AR, Albritton WL. Characterization of cell proteins of Haemophilus ducreyi by polyacrylamide gel electrophoresis. J Infect Dis 1983; 148:710-4.

9. Reymann F. Type differentiation of Haemophilus ducreyi. Acta Pathol Microbiol Scand 1950; 27:364-77. 